\title{
Çarpıntı, göğüs ağrısı ve senkop yakınmalı çocuklarda holter monitorizasyon sonuçları: Sekiz yıllık deneyim
}

\author{
Olgu Hallığlu1, Dilek Giray¹, Derya Karpuz¹, Abdullah Özyurt² \\ ${ }^{1}$ Mersin Üniversitesi, Tıp Fakültesi, Çocuk Kardiyoloji Bilim Dalı, Mersin \\ ${ }^{2}$ Mersin Kadın Doğum ve Çocuk Hastalıkları Hastanesi
}

Öz

Amaç: Çarpıntı, göğüs ağrısı ve senkop gibi disritmik semptomlarla başvuran hastalarda elektrokardiyografi tanıda yeterli olmayabilir. $\mathrm{Bu}$ durumda 24 saatlik ritim holter monitorizasyonu uygulanır. Bu çalışmanın amacı sekiz yıllık dönemde pediatrik popülasyonda disritmik semptomlarla başvuran hastalarda görülen ritim bozukluklarının tür ve sıklı̆̆ını saptamaktır. Yöntem: Çalışmada Ocak 2008- Aralık 2015 tarihleri arasında çocuk kardiyoloji ünitesine çarpıntı, gögü̈s ağrısı ve senkop şikayetleri ile başvuran, 4-17 yaş arası, 302 pediatrik hastanın 24 saatlik ritim holter monitorizasyon sonuçları değerlendirildi. Bulgular: Hastaların 237 'sinde (\%78.5) çarpıntı, 48'inde (\%15.9) senkop ve 17'sinde (\%5.6) ise göğüs ağrısı mevcuttu. Hastaların 111'inde (\%36.7) aritmi olduğu belirlendi. Çarpıntı ile başvuranlarda aritmi sıklığı \%37.1, senkop ile başvuranlarda \%39.6 ve gögüs ağrısı ile başvuranlarda ise $\% 23.5$ idi. Bu üç gruptan çarpıntı ve senkop ile başvuranlarda aritmi sıklığı göğüs ağrısı ile başvuranlara göre daha fazlaydı. Hastaların yașına göre en sık iki ritim bozukluğu incelendiğinde 10 yaș altında supraventriküler ekstrasistol sıklığı \%37 iken, 10 yaş ve üstünde bu oran \%63 idi. 10 yaş altında sadece 8 hastada (\%14.3 ) ventriküler ekstrasistol veya supraventriküler ekstrasistol ile birlikteliği saptanırken 10 yaș ve üstünde 48 hastada (\%87.5) vardı. Bu fark istatistiksel olarak anlamlı idi $(\mathrm{p}=0.025)$. Sonuç: Çarpıntı ve senkop şikayeti ile başvuran hastaların yaklaşık üçte birinde aritmi ve bunların da \%5.2'sinde ciddi aritmi saptandı. Göğüs ağrısı ile başvuran çocuklarda ailevi risk faktörleri varlığında holter EKG incelemesi yapılması gerektiği, çarpıntı ve senkop ile başvuran özellikle 10 yaş üzeri çocuklarda ise risk faktörü aranmaksızın holter monitorizasyonu yapılması gerektiği kanısına varılmıştır.

Anahtar kelimeler: Çarpıntı, gögüs ağrısı, senkop, aritmi, holter EKG

Yazının başvuru tarihi: 12.01.20217 Yazının kabul tarihi: 06.04.2017

Yazışma adresi: Dilek Giray, Mersin Üniversitesi, Tıp Fakültesi, Çocuk Kardiyoloji Bilim Dall, Mersin

Tel :0 32424100 00, Fax :0 32424100 00, E-posta : ddilekkarabulut@hotmail.com

Not :Çalışma 15.Pediatrik Kardiyoloji ve Kalp Damar Cerrahisi Kongresi'nde (13-16 Nisan 2016/ Antalya) poster bildirisi olarak sunulmuştur. 


\title{
Holter monitorization in children with the symptoms of palpitations, chest pain and syncope: An eight-year trial
}

\begin{abstract}
Aim: The electrocardiogram may not be enough in the diagnosis of patients which presenting with dysrhythmic symptoms like palpitation, chest pain, and syncope. The aim of this study was to determine the type of rhythm disorders and the incidence in the pediatric population presenting with dysrhythmic symptoms in the eight-year period during the 24-hour holter monitoring. Methods: In the study, 24-hour holter monitoring results of 302(aged 4 to 17) pediatric patients presenting to the pediatric cardiology unit with dysrhythmic symptoms in between January 2008-December 2015 were evaluated. Results: 237(78.5\%) of patients had symptom of palpitations, $48(15.9 \%)$ had syncope and $17(5.6 \%)$ had the chest pain. Arrhythmia was identified in $111(36.7 \%)$ of the patients. The incidence of arrhythmia in patients presenting with palpitations was $37.1 \%$, with syncope was $39.6 \%$ and with chest pain was $23.5 \%$. Under 10 years of age supraventricular extrasystole was detected in $37 \%$ of the patients and the ratio was $63 \%$ over the 10 years of age. Under 10 years of age only $8(14.3 \%)$ patients was detected as isolated ventricular extrasystole or together with supraventricular extrasystole, but over the 10 years of age the arrhythmia were detected in $48(87.5 \%)$ patients. This difference was statistically significant $(p=0.025)$. Conclusion: In about one-third of the patients presenting with palpitation and syncope has arrhythmia and $5.2 \%$ of them are serious. It is thought that, holter ECG examination should be done to the children presenting with chest pain if familial risk factors are present, while must be done to all patients presenting with palpitations and syncope, especially over 10 years of age even if there is not any risk factor.
\end{abstract}

Keywords: Palpitation, chest pain, syncope, arrhythmia, holter ECG

\section{Giriş}

Çocuklarda kardiyak disritmilerin tanınması genellikle aralıklı ortaya çıkması nedeniyle güçtür ve başvuru anında her zaman saptanamayabilir. Önemli kardiyak disritmilerin en yaygın belirtisi çarpıntı olmakla birlikte senkop ve gögüs ağrısı da görülebilir. holter monitörizasyonu ritim bozukluğu ile başvuran çocuklarda, oskültasyonda veya elektrokardiyografide (EKG) aritmi saptanması durumunda, ameliyat olan konjenital kalp hastalarının ve antiaritmik tedavi alan hastaların izleminde kullanılan non-invaziv bir tanı aracıdır. ${ }^{1,2}$ Kardiyak ritmin gün boyunca izlenmesi ile ventriküler veya supraventriküler taşikardiler, sinüs bradikardisi, hasta sinüs sendromu ve diğer muhtemel semptomatik disritmiler tanınabilmektedir. ${ }^{3}$ Çarpıntı, gögüs ağrısı ve senkop yakınmaları ile başvuran çocuklarda holter gerekliliği merkezden merkeze değişen bir yaklaşıma sahiptir. $\mathrm{Bu}$ çalışmanın amacı kliniğimize

Mersin Univ Saglık Bilim Derg 2017;10(2) disritmik semptomlarla başvuran çocuklardaki aritmi sıklığını, semptomlarla ilişkisini ve dağılımını araştırmaktır.

\section{Yöntem}

Çalışmada Ocak 2008- Aralık 2015 tarihleri arasındaki sekiz yıllık sürede üniversite hastanesi çocuk kardiyoloji ünitesine çarpıntı, göğüs ağrısı ve senkop şikayetleri ile başvuran hastalar retrospektif olarak tarandı. Disritmik şikayetler ile başvuran ve şikayetlerin siklığ ve süresi nedeniyle 24 saatlik ritim holter monitorizasyonu yapılması gerektiğine karar verilen hastaların kayıtları retrospektif olarak incelendi. Standart ambulatuvar üç kanallı (V1, V5 ve aVF) 24 saat ritim holter kayıt cihazı kullanılarak monitorizasyonları yapılmış olan 4-17 yaş arası (ortalama $11.6 \pm 3.3$ yaş) toplam 302 pediatrik hastanın (169K, 133E) holter kayıtlarına ulaşıldı. Hastaların demografik özellikleri hasta bilgi sisteminden kaydedildi. Bu çalışma için 
hastane yerel klinik araştırmalar etik kurulundan onay alındi ( 2016/87).

İstatiksel analiz: Elde edilen verilerin dağılımına bakıldıktan sonra ortalama veya ortanca, standart sapma, en küçük en yüksek değer ve yüzde olarak sonuçlar özetlendi. Niteliksel verilerin analizinde "ki-kare testi" kullanıldı. $\mathrm{p}<0.05$ değeri istatistiksel olarak anlamlı kabul edildi.

\section{Bulgular}

Çalışmaya alınan hastaların 169'u (\%56) kız, 133'ü (\%44) erkekti. Hastaların yaşları 4-17 yaş arasında (ort=11.6 \pm 3.3 ) değişmekteydi. Her üç hasta grubunda da yaş dağılımı açısından anlamlı farklılık yoktu ( $p>0.05)$ (Tablo 1). Hastaların başvuru şikayetlerine bakıldığında 237'sinde (\%78.5) çarpıntı, 48'inde (\%15.9) senkop ve 17'sinde (\%5.6) ise göğüs ağrısı mevcuttu. Çarpıntı ve senkop şikayetlerinin kız ve erkeklerde görülme sıklıkları arasında anlamlı fark yoktu ancak gögüs ağrısı erkeklerde kızlardan anlamlı oranda daha sıktı $(\mathrm{p}<0.05)$.

Hastaların ritim holter EKG'leri değerlendirildiğinde 111 hastada (\%36.7) ritim bozukluluğunun olduğu belirlendi. Bu üç hasta grubunda çarpıntı ile başvuranlarda aritmi sıklığı \%37.1 (88 hasta), senkop ile başvuranlarda \%39.6 (19 hasta) ve gögüs ağrısı ile başvuranlarda ise \%23.5 (4 hasta) idi. Buna göre aritmi görülme sıklığı çarpıntı ve senkop ile başvuranlarda göğüs ağrısı ile başvuranlara göre daha fazla olmakla birlikte istatistiksel fark saptanmadı ( $p>0.05)$.

Tablo 1. Demografik özellikler

\begin{tabular}{llll}
\hline Cinsiyet & Kız (\%) & Erkek (\%) & $\mathrm{p}$ \\
Yaş & $169(56)$ & $133(44)$ & 0.078 \\
Başvuru şikayeti & $11.7 \pm 3.28$ & $11.47 \pm 3.28$ & 0.627 \\
$\quad$ Çarpıntı & $136(80.5)$ & $101(75.9)$ & 0.076 \\
$\quad$ Senkop & $28(16.6)$ & $20(15)$ & 0.074 \\
$\quad$ Göğüs ağrısı & $5(3)$ & $12(9)$ & $\mathbf{0 . 0 4 5}$ \\
$\quad$ Aritmi sıklığı & $59(34.9)$ & $52(39.1)$ & 0.265 \\
\hline
\end{tabular}

Çarpıntı ve göğüs ağrısı ile gelenlerde en slk görülen ritim bozukluğunun ventriküler ekstrasistol (VES) ve onu takip eden oranlarda supraventriküler ekstrasistol (SVE) idi. Senkop ile başvuranlarda ise bu iki ritim bozukluğu aynı sıklıktaydı (\%12.5). Ritim bozukluklarının semptomlara göre dağılımı, ritim bozukluklarının her bir grup içindeki oranları Tablo 2'de özetlenmiştir.

Hastaların 16'sında (\%5.2) supraventriküler taşikardi, pre-eksitasyon, mobitz tip 1 ve 2 blok, pause, ventriküler taşikardi, uzun QT sendromu ve atrial flutter gibi klinik olarak önemli ritim bozuklukları saptandı. Göğüs ağrısı grubunda ise ciddi aritmiye rastlanmadı.

Çarpintı ile gelen hastaların \%37.1'inde disritmi saptandı. Bunlardan klinik olarak önemli olan ritim bozukluğu oranı ise \%5.4 idi ve en sık VES ile SVE saptandı. Senkop şikayeti ile başvuran hastalarda ritim bozukluğu sıklığı \%39.6, ciddi disritmi sıklı̆̆ ise \%6.25 idi. Bu hasta grubunda da en sik VES ve SVE saptand. Gögüs ağrısı ile başvuranlarda ise disritmi saptanma oranı \%23.5 iken herhangi ciddi ritim bozukluğu izlenmedi (Tablo 2). 
Tablo 2. Semptomlara göre ritim bozukluğu tipleri ve sıklıkları

\begin{tabular}{lllll}
\hline Ritim bozukluğu & $\begin{array}{l}\text { Çarpıntı (\%) } \\
\mathrm{n}=237\end{array}$ & $\begin{array}{l}\text { Göğüs ağrısı } \\
(\%) \mathrm{n}=17\end{array}$ & $\begin{array}{l}\text { Senkop (\%) } \\
\mathrm{n}=48\end{array}$ & $\begin{array}{l}\text { Siklık (\%) } \\
(\mathrm{n}=302)\end{array}$ \\
VES & $29(12.2)$ & $2(11.7)$ & $6(12.5)$ & $37(12.3)$ \\
SVE & $28(11.8)$ & $1(5.9)$ & $6(12.5)$ & $35(11.6)$ \\
SVE + VES & $14(5.9)$ & $1(5.9)$ & $5(10.4)$ & $19(6.3)$ \\
Sağ Dal Bloğu & $4(1.7)$ & - & - & $4(1.3)$ \\
Pre-eksitasyon & $4(1.7)$ & - & - & $4(1.3)$ \\
SVT & $3(1.3)$ & - & - & $3(1.0)$ \\
Mobitz Tip2 Blok & $2(0.8)$ & - & $1(2.1)$ & $3(1.0)$ \\
VT & $1(0.4)$ & - & $1(2.1)$ & $2(0.7)$ \\
Mobitz Tip1Blok & $1(0.4)$ & - & - & $1(0.3)$ \\
Pause & $1(0.4)$ & - & - & $1(0.3)$ \\
Atriyal flutter & - & - & - & $1(0.3)$ \\
Uzun QT & $1(0.4)$ & - & - & $1(0.3)$ \\
Aritmili hasta toplam & $88(37.1)$ & $4(23.5)$ & $19(39.6)$ & $111(36.7)$ \\
\hline VES:ventriküler ekstra sistol, SVE:supraventriküler ekstrasistol, SVT:supraventriküler taşikardi, \\
VT:ventriküler taşikardi
\end{tabular}

Gelis semptomlarına bakılmaksızın tüm hastalar değerlendirildiğinde en slk saptanan ritim bozuklukları \%12.3 (37 hasta) ile SVT ve \%11.6 (35 hasta) ile VES idi. Hastaların 19'unda (\%6.3) ise bu iki ritim bozukluğunun birlikte bulunduğu belirlendi. Bunların dışındaki diğer ritim bozukluklarının çalışmaya alınan tüm hasta grubunda görülme sıklıkları ise Tablo 2'de belirtilmiștir.

Tüm gruplarda birlikteliği en sık görülen disritmiler VES ve SVE idi. Bu iki ritm bozukluğunun birlikte görülme oranı ise senkop grubunda (\%8.3) diğer iki gruptan (\%5.9) daha yüksek olmakla birlikte istatistiksel fark saptanmadı.

VES ve SVE saptanan hastaların yaşına göre ritim bozukluğu incelendiğinde 10 yaş altında SVE sıklığı \%37 iken, 10 yaş ve üstünde bu oran $\% 63$ idi. 10 yaş altında sadece 8 hastada (\%14.3) VES veya VES ile SVE birlikteliği saptanırken 10 yaş ve üstünde 48 hastada (\%87.5) satandı. Bu fark istatistiksel olarak anlamlı idi ( $\mathrm{p}=0.025)$.

\section{Tartışma}

Çarpıntı, presenkop, senkop, göğüs ağrısı gibi semptomlar genellikle disritmiyi düşündüren yakınmalardır. ${ }^{1,2}$ Disritmilerin paroksismal özellikleri nedeniyle tanıda rutin EKG yetersiz kalabilmektedir. ${ }^{3}$ Ayabakan ve arkadaşlarının ${ }^{4}$ yaptığ çalışmada holter monitorizasyonu yapılan hastalarda en sık görülen disritmik semptom olarak çarpıntı saptanmıştır. Çalışmamızda da çarpıntı \%78.5 ile ilk sırayı alıyordu.

Çocuklardaki semptomları ritim bozukluğuna bağlamanın zor olduğu bilinmektedir. Ciddi ritim bozuklukları genellikle konjenital kalp hastalığı bulunan olgularda saptanmaktadır. Postoperatif, kardiyomiyopatili veya konjenital kalp hastalığı olanlar disritmi yönünden yüksek riskli gruptadır ve bu olgular asemptomatik bile olsalar erken teşhis ve tedavi için ritim bozuklukları açısından yakın izlenmelidir. Holter monitorizasyonu disritmilerin tanı ve izleminde en özgül ve en duyarlı tanı aracıdır. ${ }^{5}$ Holter monitorizasyonun EKG'de aritmi saptananlarda ve riskli hastalarda kullanılabilirliğinin yüksek olduğu bildirilmektedir. $^{2} \quad$ Kardiyak ritmin incelenmesi ile SVT, VT, sinüs bradikardisi, hasta sinüs sendromu ve diğer muhtemel semptomatik disritmiler tanınabilmektedir. ${ }^{3}$ Ferreira ve ark. ${ }^{1}$ semptomları olan hastaların \%24'ünde holter monitorizasyonu ile aritmi saptamışlardır. Çalışmamızda ise 
semptomatik olan 111 hastada (\%36.7) ritim bozukluluğunun olduğu belirlendi.

$\begin{array}{rrr}\text { Kardiyak } & \text { disritmilerin en yaygın } \\ \text { bulgusu olan çarpıntı, } & \text { kardiyoloji }\end{array}$ doktorlarının tanı koymada en çok zorlandığı yakınmalardandır. Çarpıntı ile başvuran pediatrik hastaların \%5.7-35'ine holter ile tanı konulabilmektedir.2,5 Çalışmamızda çarpıntı nedeniyle başvuranların \%37.1'inde disritmi saptandı. Bunlardan klinik olarak önemli olan ritim bozukluğu oranı ise \%5.4 idi. Yapısal olarak normal olan bir kalpte disritmiye bağlı senkop nadirdir. Kliniğimizde senkop nedeniyle başvuran olguların çoğuna holter monitorizasyonu uygulanmaktadır. Çalışmamızda senkop şikayeti ile başvuran hastalarda ritim bozukluğu sıklı̆̆ $\% 39.6$, ciddi disritmi sıklığı ise \%6.25 idi. Gögüs ağrısı ile başvuranlarda ise disritmi saptanma oranı \%23.5 iken herhangi ciddi ritim bozukluğu izlenmedi. Yapılan çalışmalarda da göğüs ağrısında altta organik bir kalp hastalığı yoksa holter monitorizasyonunun çok yararlı bilgi vermediği vurgulanmaktadır.2,6,7 Kliniğimizde de disritmik semptomlardan göğüs ağrısı olan hastalara holter monitorizasyonu endikasyonu daha ender konulduğundan hasta sayısı bu grupta düşüktü.

Ventriküler ve supraventriküler ekstra atımlar çocuklarda sık görülen ritim problemleridir. Çalışmamızda da ritim bozukluğu saptanan hastalarda en sık VES (\%33) ve SVE (\%31.5) belirlenmiştir. Sağlıklı çocuklarda da değișen oranlarda (\%17-48) ritim bozukluğu olduğu bilinmektedir.1,7 $\mathrm{Bu}$ nedenle önemli olan hayatı tehdit eden ve tedavi gerektiren ritim bozukluklarının saptanmasıdır. Güven ve ark. ${ }^{7}$ bir çalışmada asemptomatik ve EKG'de disritmi saptanan olguların \%24'ünde SVT, multifokal VES, kısa VT gibi klinik önemi olan ritim bozuklukları olduğunu göstermişlerdir. Yine aynı çalışmada eşlik eden EKG bulgusu yoksa hastada klinik olarak önemli ritim bozukluğunun görülme oranının düşük olduğunu bildirmişlerdir. Çalışmamızda EKG korelasyonu yapılmamıştır ancak hastaların \%5.2'sinde klinik önemi olan ve tedavi gerektiren disritmi saptanmıștır.
Disritmilerin dağılımı çocukluk çağında yaşa göre farklılık göstermektedir. Özellikle VES'lerin görülme sıklığı yaş ile artarken, SVE, SVT ve komplet AV blok daha küçük yaşlarda karşımıza çıkmaktadır.4,8,9 Çalışmamızda ise hem SVE hem de VES 10 yaş üzerinde fazla olmakla birlikte SVE sıklığ açısından anlamlı fark yoktu. Ancak 10 yaş üzerindeki VES sıklığı düşük yaş grubuna göre anlamlı derecede artmıştı.

Çalışmanın retrospektif olması, göğüs ağrısı grubu başta olmak üzere gruplardaki hasta sayılarının az olması bu çalışmanın kısıtlılıklarıdır. Ayrıca holter monitorizasyonunun 24 saatlik olması nedeniyle özellikle çarpıntı ve gögüs ağrısı şikayetleri ile gelen hastalarda holterin takılı olduğu 24 saatlik süreçte aritmik bir durumun gelişmemesi bu hastaların sağlıklı grubunda değerlendirilmesine neden olmaktadır.

Sonuç olarak; çalışmada çarpıntı ve senkop şikayeti ile başvuran hastaların yaklaşık üçte birinde aritmi saptanmış ve bunların da \%5.2'sinde ciddi aritmiler olduğu belirlenmiştir. Bu nedenle hastaların sadece EKG ile değerlendirmesinin yeterli olmayacağı düşünülmüştür. Ayrıca, göğüs ağrısı ile başvuran çocuklarda ailevi risk faktörleri varlığında holter EKG incelemesi yapılması gerektiği, çarpıntı ve senkop ile başvuran özellikle 10 yaş üzeri çocuklarda ise risk faktörü aranmaksızın holter monitorizasyonu yapılması gerektiği kanısına varılmıștır.

\section{Kaynaklar:}

1. Ferreira J, Luis J, Mota P, Anjos R, Meneses I, Bonhorst D, et al. Holter electrocardiography en pediatric cardiology: preliminary experience. Rev Port Cardiol 1996;15(1):27-33.

2. Hegazy RA, Ltfy WN. The value of holter monitoring in the assessment of pediatric patients. Indian Pacing Electrophysiol J 2007;7(4):204-214.

3. O'Laughlin MP. Syncope in pediatric arrhythmias. Garson A, Gillette CP, eds. Electrophysiology and Pacing, 1 nci baskı. 
Philadelphia, WB. Saunders, Co, 1990:600-616.

4. Ayabakan C, Özer S, Çeliker A, Özme S. Analysis of 2017 Holter recordings in pediatric patients. Turkish Journal of Pediatrics 2000;42(4):286-294.

5. Fleg JL, Kennedy HL. Long-term prognostic significance of ambulatory electrocardiographic findings in apparently healthy subjects greater than or equal to 60 years of age. Am J Cardiol 1992;70(7):748-751.

6. Lown B. Cardiovascular collapse and sudden cardiac death. In: Braunwald E, ed. Heart Disease. A Textbook of Cardiovascular Medicine. Philadelphia: Saunders; 1984:2.
7. Güven $H$, Levent $E$, Özyürek $A R$, Büyükinan M, Aydoğdu A, Parlar A. Two years experience of holter monitoring in children. Ege Tip Dergisi 2002;41(1):1520.

8. Levy AM, Camm AJ, Keane JF. Multiple arrhythmias detected during nocturnal monitoring in patients with congenital complete heart block. Circulation. 1977;55(2):247-253.

9. Bensen DW, Müller G. Ambulatory electrocardiography. In: Emmanoilides GC, Allen HD, Riemenschneider TA, Gutgesel HP, eds. Heart Disease in Infants, Children, and Adolescents, Including Fetus and Young Adult, 5th ed, Baltimore: Williams and Wilkins; 1995:165-172. 